\title{
Vertically-Oriented Graphene Electric Double Layer Capacitor Designs
}

John R. Miller

John R. Miller

Ronald A. Outlaw

College of William and Mary

Follow this and additional works at: https://scholarworks.wm.edu/aspubs

\section{Recommended Citation}

Miller, J. R., \& Outlaw, R. A. (2015). Vertically-oriented graphene electric double layer capacitor designs. Journal of The Electrochemical Society, 162(5), A5077-A5082.

This Article is brought to you for free and open access by the Arts and Sciences at W\&M ScholarWorks. It has been accepted for inclusion in Arts \& Sciences Articles by an authorized administrator of W\&M ScholarWorks. For more information, please contact scholarworks@wm.edu. 


\title{
Vertically-Oriented Graphene Electric Double Layer Capacitor Designs
}

\author{
John R. Miller ${ }^{\mathrm{a}, \mathrm{b}, *, \mathrm{z}}$ and Ronald A. Outlaw ${ }^{\mathrm{c}, *}$ \\ a JME, Inc., Beachwood, Ohio 44122, USA \\ ${ }^{b}$ Case Western Reserve University, Cleveland, Ohio 44106, USA \\ ${ }^{c}$ College of William and Mary, Williamsburg, Virginia 23187, USA
}

\begin{abstract}
High-voltage electric double layer capacitors (EDLCs) capable of efficient AC line-filtering have been developed. They were fabricated with vertically-oriented graphene nanosheet (VOGN) electrodes using a planar design. Two approaches were examined to series connect EDLC cells and thus achieve high-voltage operation. Electrical performance of VOGN electric double layer capacitors fabricated with an ionic liquid electrolyte was measured at temperatures up to $125^{\circ} \mathrm{C}$. Volume comparisons are made between VOGN electric double layer capacitors and aluminum electrolytic capacitors. A practical design is presented that provides the VOGN electric double layer capacitor with more than an order-of-magnitude higher ripple-current filtering performance $(120-\mathrm{Hz})$ than available from present capacitor technology.

(C) The Author(s) 2015. Published by ECS. This is an open access article distributed under the terms of the Creative Commons Attribution Non-Commercial No Derivatives 4.0 License (CC BY-NC-ND, http://creativecommons.org/licenses/by-nc-nd/4.0/), which permits non-commercial reuse, distribution, and reproduction in any medium, provided the original work is not changed in any way and is properly cited. For permission for commercial reuse, please email: oa@electrochem.org. [DOI: 10.1149/2.0121505jes] All rights reserved.
\end{abstract}

Manuscript submitted December 18, 2014; revised manuscript received January 20, 2015. Published January 30, 2015. This paper is part of the JES Focus Issue on Electrochemical Capacitors: Fundamentals to Applications.

Efficient AC line-filtering $(120 \mathrm{~Hz})$ by an electric double layer capacitor (EDLC) was first demonstrated in 2010 using electrodes of vertically-oriented graphene (VOGN) grown directly on nickel. ${ }^{1}$ This electrode material and its structure (Figure 1) reduce series resistance to an absolute minimum value and effectively eliminate distributed charge storage, i.e. porous electrode behavior with its corresponding transmission-line-like electrical response. In brief, EDLC electrodes are made by growing the VOGN on bare nickel current collectors using radio frequency plasma enhanced chemical vapor deposition of $\mathrm{CH}_{4} / \mathrm{H}_{2}$ or $\mathrm{C}_{2} \mathrm{H}_{2} / \mathrm{H}_{2}$ feed gases. ${ }^{2,3}$ Growth temperature is typically in the 550 to $850^{\circ} \mathrm{C}$ range. No catalytic seed material is required or added to the nickel surface. Growth proceeds by Volmer-Weber island impingement, ${ }^{4}$ which yields an upturned structure at carbon island boundaries. There is significant carbon dissolution into the nickel during growth that helps ensure low-resistance ohmic connection between the high-conductivity graphene sheets and the metal current collector. Typical characteristic VOGN spacing is $\sim 200 \mathrm{~nm}$ and heights $\sim 1 \mu \mathrm{m}$, a void length-to-width ratio that thwarts porous electrode behavior as found with activated-carbon. ${ }^{5}$

Generally the Raman D band to $G$ band intensity ratio decreases with growth time indicating that crystalline order of the VOGN increases with nanosheet height, which increases approximately linearly with time at growth rates of $70 \mathrm{~nm} /$ minute using $\mathrm{CH}_{4}$ and $190 \mathrm{~nm} /$ minute using $\mathrm{C}_{2} \mathrm{H}_{2} \cdot{ }^{6}$ Electrode capacitance at $120 \mathrm{~Hz}$ typically is in the 200 to $300 \mu \mathrm{F} / \mathrm{cm}^{2}$ range, depending on VOGN growth conditions and growth time. The frequency response reported for EDLCs made using other external-surface-area nanomaterials is generally below that demonstrated by VOGN grown on nickel because of higher series resistance and/or distributed charge storage behavior. ${ }^{7-12}$ State of the art commercial EDLCs, which use internal-surface-area activated carbon electrode materials, typically have a $-45^{\circ}$ phase angle at $\sim 0.2 \mathrm{~Hz}$ and show inductive behavior (positive phase angle) at $120 \mathrm{~Hz}$, rendering them totally useless for AC line filtering. ${ }^{13}$

\section{EDLC Designs}

A conventional EDLC "sandwich" design, as depicted in Figure 2, is poorly suited for capacitors made using VOGN electrodes because of low volumetric efficiency (the VOGN active material is only $\sim 1 \mu \mathrm{m}$ tall and typically the separator and current collectors are respectively 25 and $50 \mu \mathrm{m}$ thick). A planar design offers volumetric advantages because it eliminates the need for a separator and it can also reduce the current collector thickness. Photolithography has previously been used to create planar EDLCs, designs having interdigitated electrodes to minimize distributed charge storage effects. ${ }^{14,15}$ In this work, we created two electrodes from one by cutting a $20-\mu \mathrm{m}$-wide gap through the VOGN and $1-\mu \mathrm{m}$-thick nickel current collector under it using laser ablation. An interdigitated pattern with $200 \mu \mathrm{m}$ finger widths was cut as shown in Figure 3a, which became a single EDLC cell once it was covered with electrolyte (Figure $3 b$ ).

With this design a solid-state electrolyte is preferred over a liquid electrolyte because it will not flow away from the patterned region after being deposited. Figure $3 \mathrm{c}$ shows capacitance versus frequency of a capacitor with this pattern measured using a gelled aqueous electrolyte. Capacitive behavior is clearly retained at frequencies above $1 \mathrm{kHz}$. Ultimately our plan is to use a solid-state ionic liquid electrolyte, ${ }^{16-19}$ which should allow high temperature operation and potentially higher cell operating voltage.

\section{Charge Storage Enhancement}

The VOGN structure shown in Figure 1 is quite open-graphene nanosheets are $\sim 1 \mu \mathrm{m}$ tall and spaced by $\sim 0.2 \mu \mathrm{m}$. Thus voids between nanosheets are larger than required for efficient capacitor operation at high frequency. One approach to increase areal capacitance density of a VOGN electrode would be to add charge storage material on the VOGN surfaces and/or in the voids between the graphene nanosheets. Key requirements to maintain high-frequency operation are: 1) the charge storage material must be connected ohmically to the graphene nanosheets with minimal electronic resistance, and 2) the material must be added in such a way that it does not create significant distributed charge storage behavior, which can arise from rough surfaces ${ }^{19}$ and densely packed particulate. ${ }^{21}$ Examples of possible charge storage material include carbon black to enhance electric double layer charge storage, or materials like polythiophene, ruthenium oxide, and manganese oxide that provide pseudocapacitance charge storage.

Cabot SC3 carbon black was used in this study because of its good electronic conductivity, high surface area $\left(\sim 1800 \mathrm{~m}^{2} / \mathrm{g}\right)$, and its demonstrated performance as an EDLC charge storage material. ${ }^{22,23}$ 

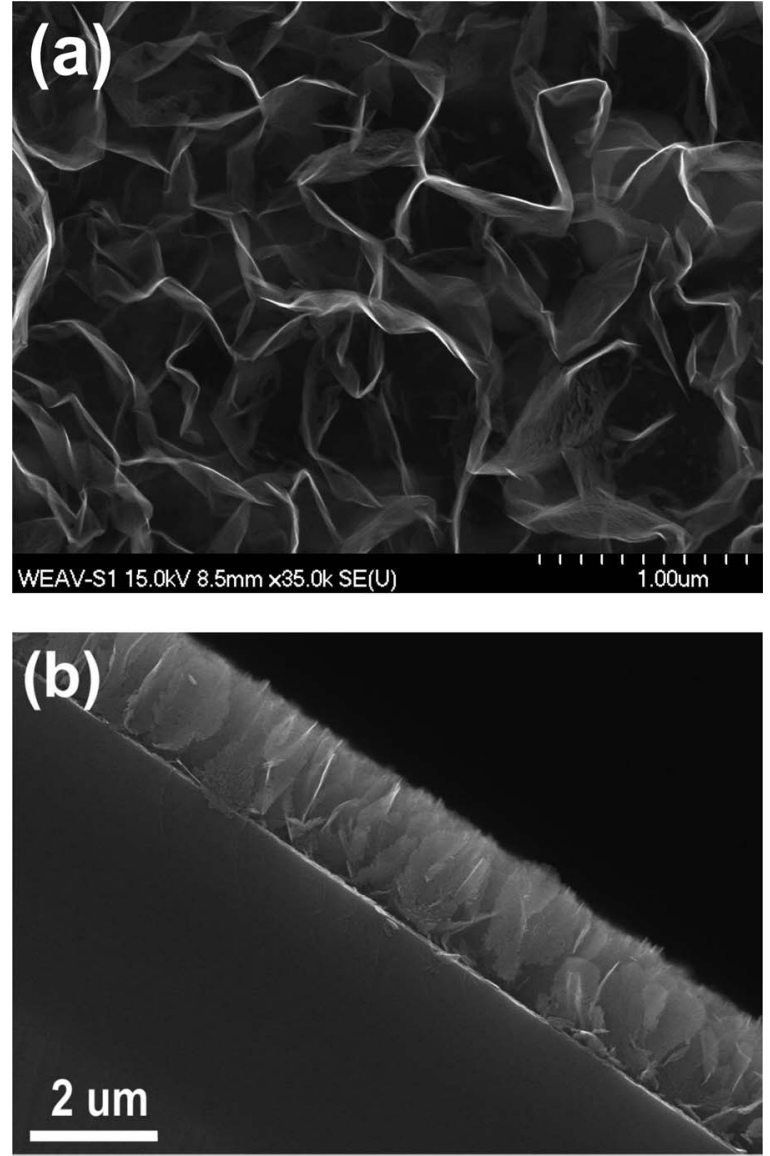

Figure 1. SEM micrographs of vertically oriented graphene nanosheets (VOGN) grown on nickel. 1a: Plan view. 1b: Cross section of VOGN grown on nickel-coated silicone (cleaved).

Single electrode capacitance density with acetonitrile-solvent electrolyte was $68 \mathrm{~F} / \mathrm{cm}^{3}{ }^{24}$ Thus a $1-\mu \mathrm{m}$-thick, $1 \mathrm{~cm}^{2}$ area electrode of SC3 carbon black using acetonitrile-solvent electrolyte would have a DC capacitance of $\sim 6.8 \mathrm{mF}$. Symmetric EDLCs with $1-\mathrm{cm}^{2}$-area, $1-\mu \mathrm{m}$-thick SC3 carbon black electrodes with acetonitrile-solvent electrolyte would have a capacitance that is one-half this value, i.e. $3.4 \mathrm{mF}$.

In general carbon black is comprised of aggregates of nearspherical, $\sim 10$-nm-diameter primary particles that form aggregates in sizes ranging from a single to tens to hundreds of primary particles. The surface area of SC3 carbon black arises primarily from porosity within each primary particle with some additional area coming from the exterior surface. Surfaces that store charge in carbon black are rapidly accessible because of the very small size of the primary particles. This minimizes distributed charge storage effects and makes this material well suited for high-frequency operation.

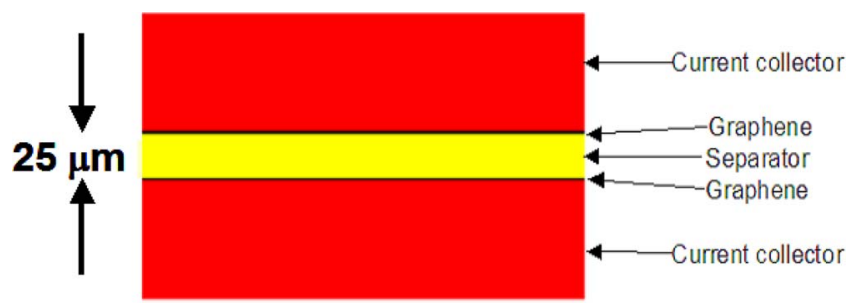

Figure 2. Cross section of an electric double layer capacitor with a "sandwich" design and using vertically oriented graphene electrodes. Note that most of the volume is occupied by the separator and the current collectors.
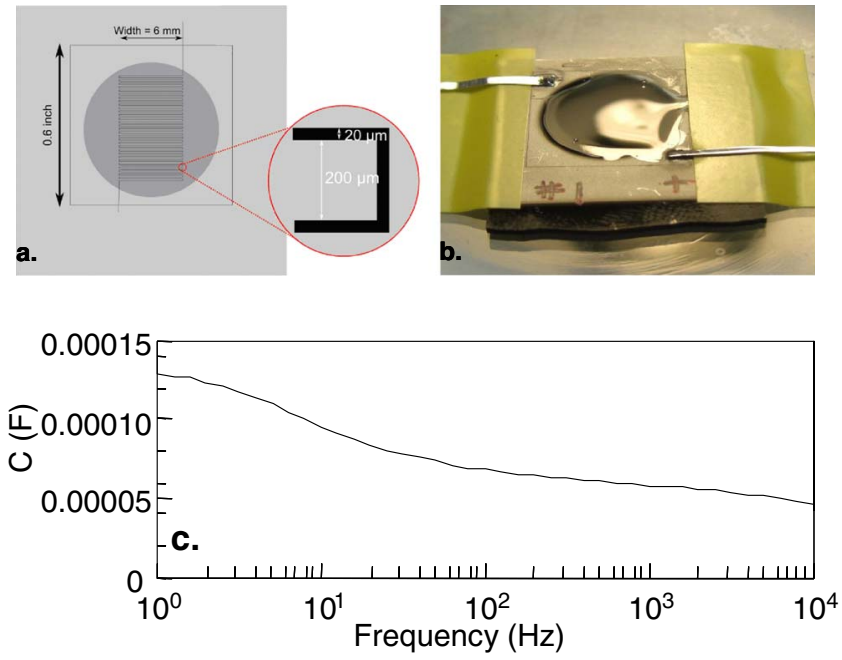

Figure 3. Planar electric double layer capacitor prototype with vertically oriented graphene electrodes and a gelled aqueous electrolyte. 3a: Interdigitated electrode pattern created by laser ablating $20-\mu \mathrm{m}$-wide gaps through the VOGN electrode and nickel current collector below it. 3b: Photograph of the completed prototype with attached electrical leads. 3c: Measured capacitance of the prototype capacitor. Capacitive behavior is retained to high frequency.

Many approaches are available to deposit sub-micrometer-thick layers of carbon black. We investigated aerosol spray, electrospray, liquid drop coating, dip coating, and ink jet printing to apply the SC3 carbon to the VOGN surface. All of these processes rely on dispensing a liquid suspension of the charge storage material. Suspension preparation involved mechanical crushing the SC3 to eliminate large agglomerates followed by ultrasonic homogenization in a liquid for various lengths of time. Several alcohols and n-methylpyrrolidone (NMP), sometimes together and always without binders or surfactants, were used to make the suspensions. Important factors included suspension stability against settling, the ability to wet the VOGN surfaces, and the drying rate after dispensing.

The plan-view SEM micrographs in Figure 4 shows VOGN surfaces with different amounts of SC 3 carbon black applied by electrospray deposition of a butanol suspension. Dispensing was at a constant $1 \mathrm{ml}$ per hour rate that was controlled by a syringe pump. The distance between the spray nozzle and the VOGN surface was $3.8 \mathrm{~cm}$ and the applied potential $10.5 \mathrm{kV}$. As shown in Figure 4, the carbon black agglomerates are extremely small-their size is only a very small fraction of the $\sim 200 \mathrm{~nm}$ distance separating the nanosheets. With increased deposition time there is a progressive accumulation of the carbon black near the top edges of the vertically oriented graphene. After 4 minutes of electrospray deposition, VOGN voids have become partially obscured by the carbon black accumulation, and after 5 minutes, totally obscured. This behavior of material accumulation near the top of the VOGN is not surprising since deposition is controlled by an imposed electric field, which is strongest at the top edge of the graphene.

Figure 5 is a plot of capacitance versus frequency for EDLCs fabricated using $1-\mathrm{cm}^{2}$-area VOGN electrodes with different amounts of carbon black applied by electrospray deposition. Measurements were made using 30-weight-percent $\mathrm{KOH}$ electrolyte with a $25-\mu \mathrm{m}$ thick microporous separator. Capacitance values were derived from impedance data by assuming a series-RC circuit model, i.e. $\mathrm{C}=$ $-1 /\left(2 \pi f Z^{\prime \prime}\right)$ where $f$ is the frequency in $\mathrm{Hz}$ and $Z^{\prime \prime}$ is the imaginary part of the impedance. Capacitance upturn in the $10^{4}$ to $10^{5} \mathrm{~Hz}$ region of this figure is an artifact of the circuit model (where $Z^{\prime \prime}$ passes through zero) and should be ignored. Capacitance increases in a monotonic fashion with deposition time (i.e. with the mass of deposited carbon black). The $120 \mathrm{~Hz}$ capacitance value is plotted versus deposition time in Figure 6, which shows straight-line increase for the first three minutes before deviation from linearity. Capacitance after three minutes of 

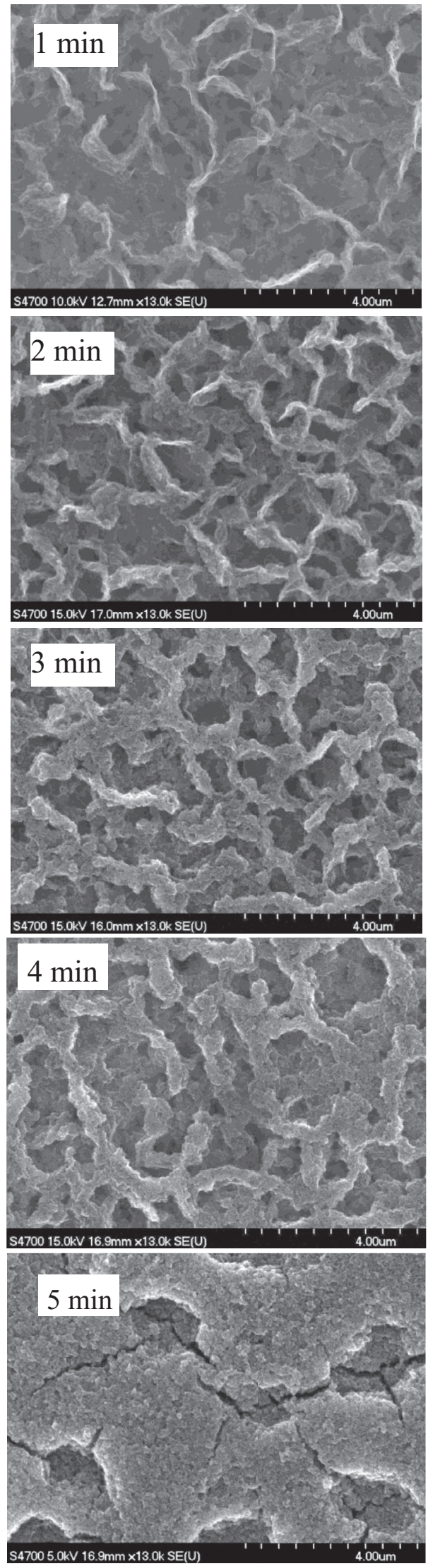

Figure 4. Plan view SEM micrographs of VOGN electrodes containing carbon black applied for five different times using electrospray deposition. Note the preferential accumulation at the top edges of the VOGN structures.

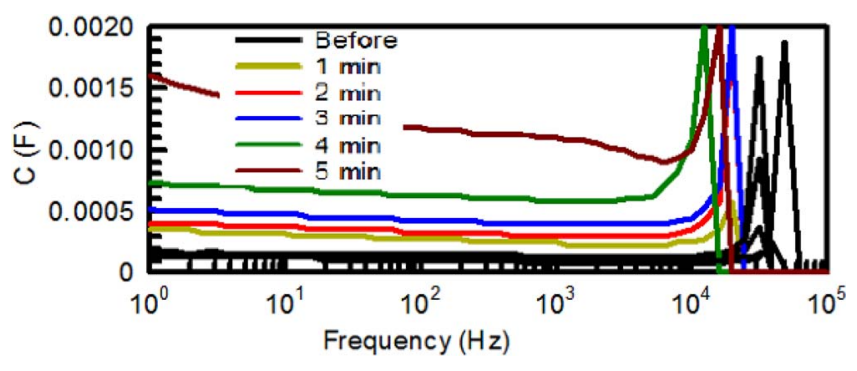

Figure 5. Capacitance versus frequency for capacitors made with electrodes shown in Figure 4. Electrical response of the capacitor made with 5-minuteelectrospray electrodes is different from the other capacitors having less carbon black.

deposition was $\sim 400 \mu \mathrm{F}$ compared with an initial value of $\sim 100 \mu \mathrm{F}$, which is well below the $6.8 \mathrm{mF}$ calculated value for a $1-\mu \mathrm{m}$-thick, $1 \mathrm{~cm}^{2}$ SC3 carbon black layer. Measured electrical behavior appears to be consistent with the Figure 4 SEM observations.

Liquid drop coating was performed by dispensing a measured volume of carbon black suspension onto the VOGN surface, relying on natural wetting forces to spread it around, then evaporating the solvent to affix the carbon black. Since no electric field was imposed with this approach, improved coating uniformity was expected and observed as shown in Figure 7. For this sample, $\sim 5 \mu l$ of an NMP-butanol carbon black suspension was dispensed onto the $1 \mathrm{~cm}^{2}$ VOGN electrode using a precision micropipette and dried at $60^{\circ} \mathrm{C}$. A second $\sim 5 \mu 1$ of suspension was added and dried. This sequence was repeated five times with device capacitance at $120 \mathrm{~Hz}$ increasing by $\sim 100 \mu \mathrm{F}$ each time. As shown in Figure 7, carbon black deposits were consistently below the tallest graphene structures, which is in sharp contrast with the electrospray results that show preferential carbon black deposits on the tallest structures.

Liquid drop coating with different suspension concentrations and different solvent mixtures has boosted the capacitance of $1-\mathrm{cm}^{2}$ electrode symmetric devices approximately tenfold to $\sim 2 \mathrm{mF}$, which still falls short of the value calculated for the SC3 carbon black.

A schematic of carbon black filled VOGN electrode produced by these two methods is shown in Figure 8. Electrospray deposition yields a dense carbon black layer in the region around the top of the graphene nanosheets while the liquid drop method appears to disperse the carbon black material more evenly in the voids and over the surface. Liquid drop deposition appears to be better suited for charge storage enhancement of VOGN electrodes.

\section{Electrospray - Carbon Black in Butanol}

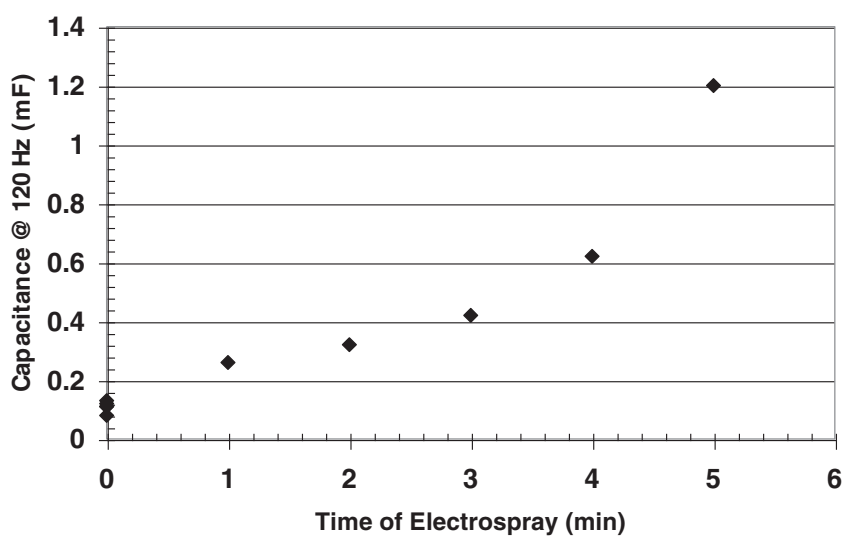

Figure 6. Capacitance at $120 \mathrm{~Hz}$ for the five capacitors made with the Figure 4 electrodes. Note the deviation from linear behavior for deposition times longer than three minutes. 


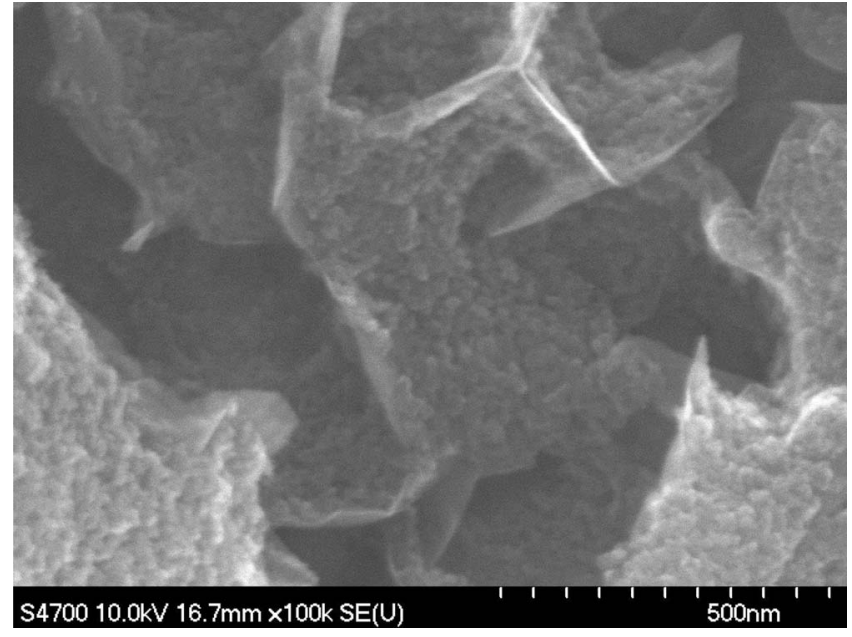

Figure 7. SEM micrograph (plan view) of a VOGN electrode coated by the liquid drop method. The deposited suspension contained NMP, butanol, and carbon black. Drying was performed at $60^{\circ} \mathrm{C}$. Note that top edges of the VOGN structures remain uncoated.

\section{Multi-Cell Design}

EDLC cells, like battery cells, operate at low voltage. Thus cells must be series connected to create a high-voltage capacitor. Figure 9 shows two approaches for interconnecting planar EDLC cells and thus create high-voltage EDLCs. The first approach (Figure 9a) involves stacking the Figure 3 planar cells then interconnecting them on opposite edges in an accordion-like fashion. Volumetric efficiency of the planar design is maintained in this stack as is the single cell frequency response.

The second approach involves interconnecting planar EDLC cells using metallization on the substrate. As shown (Figure 9b), interdigitated gaps are cut through the VOGN and nickel to create multiple electrically-isolated regions (six in this figure). The gaps are then individually covered with an electrolyte, making sure that each electrolyte band does not touch its neighbor. Figure 9c shows a cross-section of the series-connected cells, which really is a "bipolar" design in two dimensions.

Connecting $M$ cells in series (each cell rated at voltage $V_{o}$ with capacitance $C_{o}$ and series resistance $R_{o}$ ) using either approach yields a capacitor with a voltage rating $\mathrm{M} \bullet \mathrm{V}_{\mathrm{o}}$, capacitance $\mathrm{C}_{\mathrm{o}} / \mathrm{M}$, and series resistance $M \bullet R_{0}$. The second approach reduces the number of piece parts needed to assemble an $\mathrm{M}$-cell capacitor from $\mathrm{M}$ to one, which is a significant practical advantage, especially with high-voltage capacitors. The frequency response of a multi-cell capacitor, using either

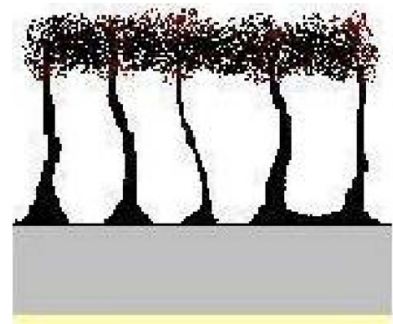

a.

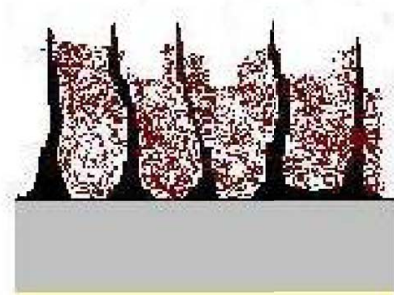

b.
Figure 8. Schematic cross-section of VOGN electrode filled with carbon black charge storage enhancer created by two different approaches; 8a: Electrospray deposition, and 8b: Liquid drop coating. a.
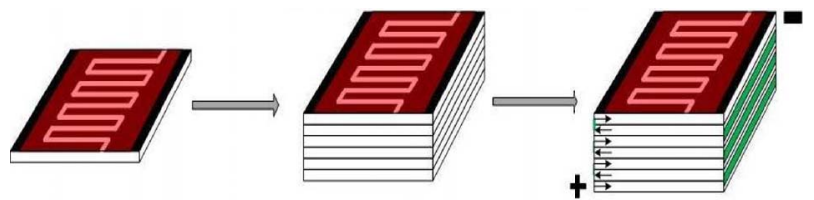

b.

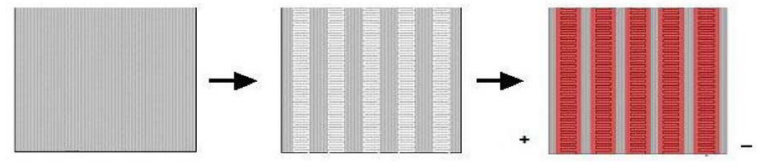

c.

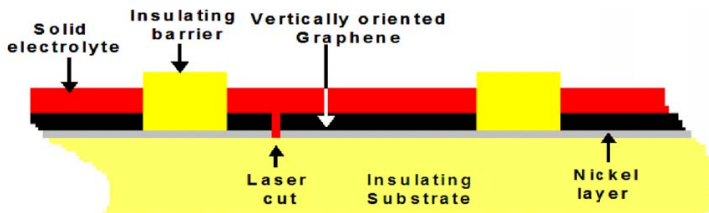

Figure 9. Two approaches for series connecting single EDLC cells having VOGN electrodes. 9a: Stacking single planar cells then interconnecting them on opposite edges in an accordion-like fashion, 9b: Series connecting cells using the substrate metallization. Shown is a capacitor having five cells in series; 9c: cross-section of capacitor shown in $9 \mathrm{~b}$ with current flow paths.

approach, will be nearly identical to that of one of its constituent cells. Voltage-balance resistors can be readily added in the second design using, for instance, thick-film printing followed by laser trimming.

\section{Capacitor Size Comparison}

It is informative to compare the volume of high-frequency VOGN electric double layer capacitors to the volume of a comparably-rated aluminum electrolytic capacitors presently used in AC line-filtering applications. High-voltage VOGN capacitors have not been produced but it is straight-forward to derive their expected size to make this comparison. Using the Figure $9 \mathrm{~b}$ planar design with $3.0 \mathrm{~V}$ per cell operation, $2.5 \mathrm{mF} / \mathrm{cm}^{2}$ areal capacitance density, $50 \mu \mathrm{m}$ total thickness (substrate, VOGN capacitor, and protective cover), and ignoring gap capacitance loss and balancing resistor volume, the calculated capacitance per volume $\left(\mu \mathrm{F} / \mathrm{cm}^{3}\right)$ is $1.08 / \mathrm{V}^{2}$ where $\mathrm{V}$ is the voltage rating. This equation is plotted in Figure 10 along with commercial aluminum electrolytic capacitor values. Volumetric advantages of an EDLC over an electrolytic capacitor are available for voltages below $\sim 100 \mathrm{~V}$.

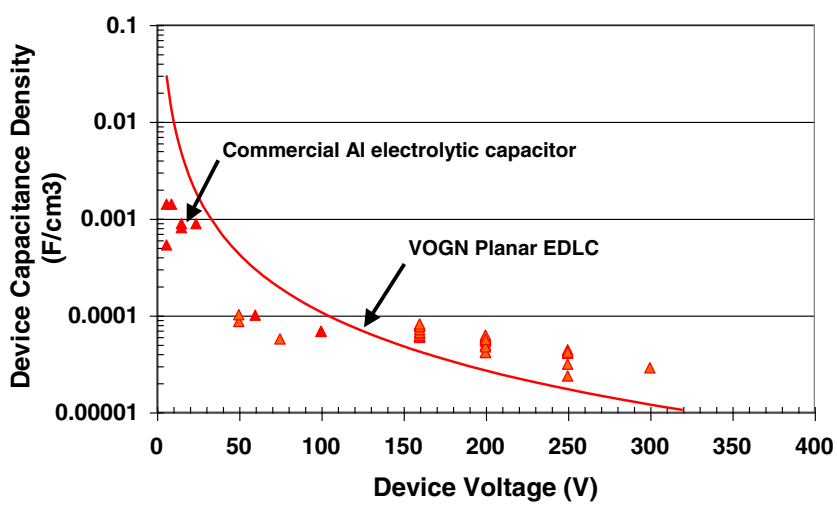

Figure 10. Volumetric comparison of planar VOGN-electrode EDLCs (red line) with commercial aluminum electrolytic capacitors (triangles). The EDLC will be smaller than an aluminum electrolyte capacitor having the same rating for voltages below $\sim 100 \mathrm{~V}$. 


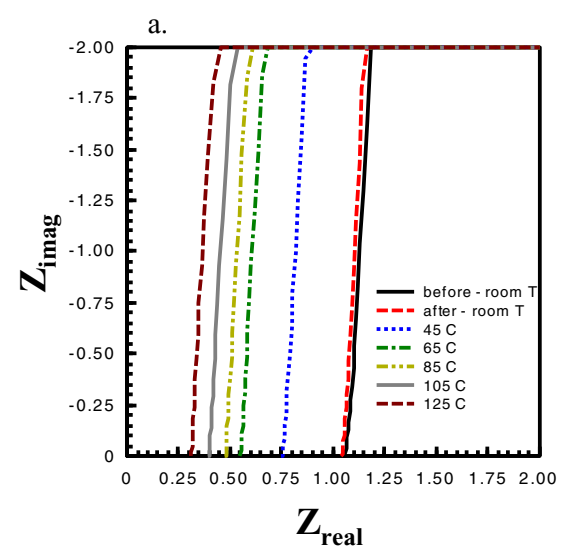

b.

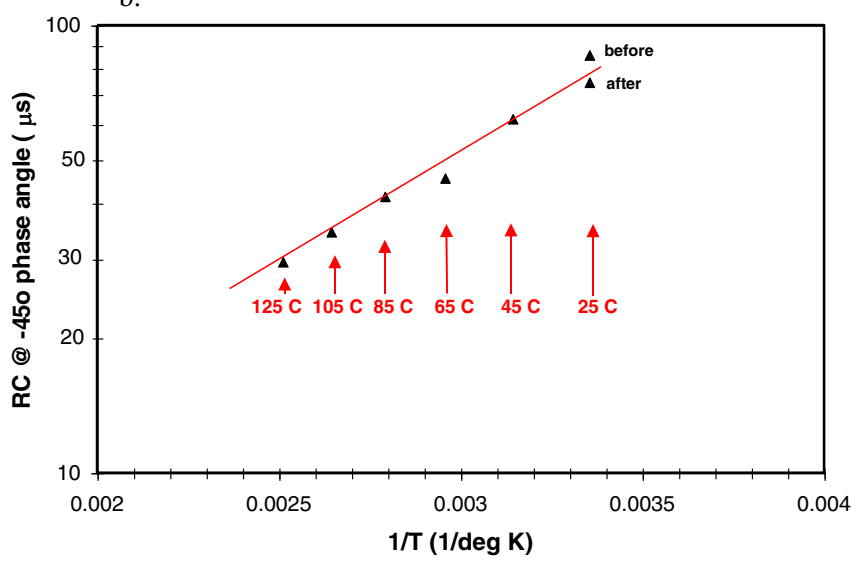

Figure 11. EDLC with VOGN electrodes in a symmetric sandwich design tested with a phosphonium ionic liquid electrolyte to $125^{\circ} \mathrm{C}$. 11a: Complex plane plot of the impedance measured at six temperatures. Data shown spans the $1 \mathrm{kHz}$ to $45 \mathrm{kHz}$ frequency range. Absolutely no porous electrode behavior is shown. Equivalent series resistance decreases with increasing temperature. 11b: Plot of the capacitor response time versus one over the absolute temperature. Capacitor response time has an Arrhenius relationship. In comparison, commercial EDLCs have an RC product that typically is in the $0.3 \mathrm{~s}$ to $2 \mathrm{~s}$ range.

\section{High-Temperature Performance}

Some aluminum electrolytic capacitors are rated for continuous operation at $125^{\circ} \mathrm{C}$. Popular electric double layer capacitors, on the other hand, are rated for $70^{\circ} \mathrm{C}$ or lower temperature operation. Consequently, electrolytes used in commercial EDLCs appear to be unsuitable for VOGN electric double layer capacitors developed to replace AC line-filtering capacitors. Ionic liquids represent a class of materials that have potential, when used as an EDLC electrolyte, to increase the operating temperature. We evaluated the performance of a symmetric VOGN capacitor using a phosphonium ionic liquid electrolyte at temperatures up to $125^{\circ} \mathrm{C}$. This electrolyte had a melting temperature of $-10.9^{\circ} \mathrm{C}$, temperature stability to $396^{\circ} \mathrm{C}$, and a room-temperature conductivity of $15.2 \mathrm{mS} / \mathrm{cm}$. Figure 11 a shows a complex-plane plot of the impedance at room temperature and at five higher temperatures. Absolutely no distributed charge storage behavior is displayed at any of the temperatures. Equivalent series resistance decreased with increasing temperature while capacitance increased with increasing temperature. The characteristic response time of this capacitor, i.e. its RC-time-constant calculated at a frequency where the phase angle was $-45^{\circ}$, was $\sim 80 \mu \mathrm{s}$ at room temperature and decreased in an Arrhenius manner to $\sim 30 \mu \mathrm{s}$ at $125^{\circ} \mathrm{C}$ (Figure $11 \mathrm{~b}$ ). Thus, power performance of this capacitor increases with operating temperature, which is opposite to the behavior exhibited by many conventional electrolytic and film capacitors. A primary need is a solid-state ionic liquid electrolyte suit-

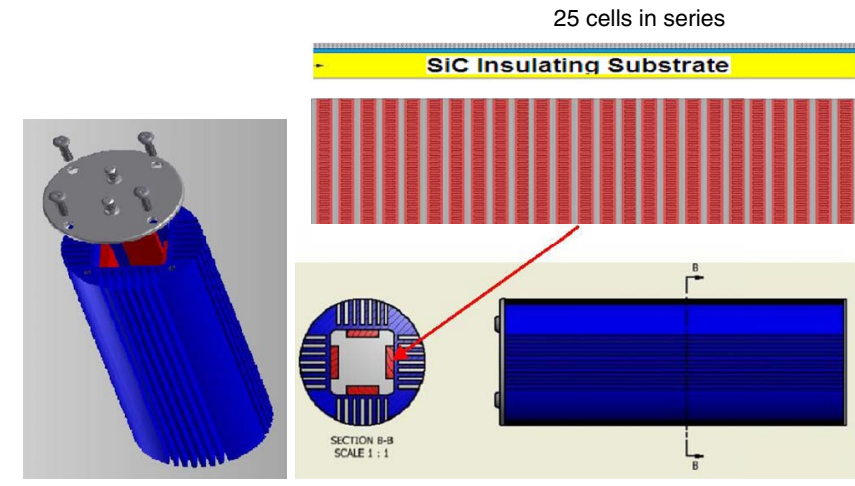

Figure 12. Conceptual design for a capacitor having high ripple current performance. Heat flow is through a thin planar substrate and directly to cooling fins.

able for the planar VOGN electric double layer capacitor with stable operation up to $125^{\circ} \mathrm{C}$.

\section{High-Ripple-Current Capacitor Design}

Aluminum electrolytic capacitors used in AC line-filtering applications are often sized by their ripple-current capability rather than by their filtering ability. Consequently, capacitance values are often much greater than needed in these applications. Thus capacitor volume (and ultimately capacitor cost) could be lowered if the filtering capacitor was better able to shed internally-generated heat. Figure 12 shows a conceptual design of a multi-cell filtering capacitor optimized to shed heat. It is a multi-cell EDLC, as described before, but fabricated on a high-conductivity $\mathrm{SiC}$ substrate rather than an alumina substrate and thermally anchored directly to cooling fins. Then generated heat flows through high-conductivity materials for a distance that is less than one millimeter. In contrast, generated heat in aluminum electrolytic capacitors (typically having a spiral-wound construction) flows through low-conductivity materials for long distances (often many centimeters). Model calculations suggest that a VOGN capacitor with the "Figure 12 design" could operate at a very high ripple-current level, likely more than an order of magnitude higher than possible with present large-format aluminum electrolytic capacitors.

\section{Summary}

High-voltage electric double layer capacitors (EDLCs) designed for efficient AC line-filtering were described and performance data was reported. These devices rely on vertically-oriented graphene (VOGN) electrodes and use a planar design. Two approaches were examined to series connect EDLC cells for high-voltage operation. Electrical performance measurements of VOGN electric double layer capacitors with phosphonium ionic liquid electrolyte are reported to temperatures up to $125^{\circ} \mathrm{C}$. Volume comparisons between VOGN electric double layer capacitors and aluminum electrolytic capacitors show that the EDLC is likely to be smaller when the operating voltage is below $\sim 100 \mathrm{~V}$. Planar VOGN electric double layer capacitors likely will offer greatly enhanced ripple-current filtering performance, perhaps to levels ten-times higher than available from present capacitor technology.

\section{Acknowledgments}

This material is based upon work supported in part by the US Army Research, Development, and Engineering Command (RDECOM) under Contract No. W911QX-13-C-0056.

\section{References}

1. J. R. Miller, R. A. Outlaw, and B. C. Holloway, Science 329, 1637 (2010).

2. J. R. Miller, R. A. Outlaw, and B. C. Holloway, Electrochim Acta 56, 10443 (2011). 
3. M. Cai, R. A. Outlaw, S. M. Butler, and J. R. Miller, Carbon 50, 5481 (2012).

4. M. Ohring, Materials Science of Thin Films, 2nd ed., Academic Press, 745 (2002).

5. Many references discuss porous electrode behavior including: (a) R. de Levie, Elec trochim Acta 8, 751 (1963). (b) B. E. Conway, Electrochemical Supercapacitors Scientific Fundamentals and Technological Applications, (Chapter 14), Kluwer Academic/Plenum Publishers (1999).

6. M. Cai, R. A. Outlaw, R. Quinlan, D. Premathilake, S. M. Butler, and J. R. Miller ACS Nano 8, 5873 (2014).

7. C. Niu, E. K. Sichel, R. Hoch, D. Moy, and H. Tennent, Appl. Phys. Lett. 70, 1480 (1997).

8. C. Du and N. Pan, J. Power Sources, 160, 1487 (2006).

9. C. Du and N. Pan, Nanotechnology 17, 5314 (2006).

10. L. L. Zhang, X. Zhao, M. D. Stroller, Y. Zhu, H. Ji, S. Murali, Y. Wu, S. Perales, B. Clevenger, and R. S. Ruoff, Nano Lett. 12, 1806 (2012).

11. K. Sheng, Y. Sun, C. Li, W. Yuan, and G. Shi, Sci. Rep 2, 247 (2012).

12. G. Ren, X. Pan, S. Bayne, and Z. Fan, Carbon 71, 94 (2014).

13. J. R. Miller, S. M. Butler, and S. McNeal, Proc. $46^{\text {th }}$ Power Sources Conf., pp. 380 383, Orlando, FL (June 2014).
14. J. Chmiola, C. Largeot, P. L. Taberna, P. Simon, and Y. Gogotsi, Science 328480 (April 2010).

15. Z. Niu, L. Zhang, L. Liu, B. Zhu, H. Dong, and X. Chen, Adv. Materials 25, 4035 (2013).

16. A. Guyomard-Lack, J. Abusleme, P. Soudan, B. Lestriez, D. Guyomard, and J. LeBideau, Adv. Energy Mater. 1301570 (2014).

17. M. Brachet, T. Brousse, and J. LeBideau, ECS Electrochemistry Letters 3, A112 (2014).

18. G. P. Pandey, S. A. Hashmi, and Y. Kumar, J. Electrohem. Soc. 157, A105 (2010).

19. Y. J. Kang, H. Chung, C. Han, and W. Kim, Nanotechnology 23, 289501 (2012).

20. I. D. Raistrick, Electrochemistry of Semiconductors and Electronics, J. McHardy and F. Ludwig ed., Noyes Publications, NJ, 316 (1992).

21. J. P. Candy and P. Fouillous, Electrochim Acta 26, 1029 (1981).

22. A. Krause, P. Kossyrev, M. Oljaca, S. Passerini, M. Winter, and A. Balducci, J. Power Sources 196, 8836 (2011).

23. P. Kossyrev, J. Power Sources 201, 347 (2012).

24. M. Oljaca, Cabot Corporation, Billerica, MA, USA, personal communication December 2014. 